\title{
Long term variations of extreme rainfall in Denmark and southern Sweden
}

\author{
Gregersen, Ida Bülow; Madsen, Henrik; Rosbjerg, Dan; Arnbjerg-Nielsen, Karsten
}

Published in:

Climate Dynamics

Link to article, DOI:

10.1007/s00382-014-2276-4

Publication date:

2015

Document Version

Publisher's PDF, also known as Version of record

Link back to DTU Orbit

Citation (APA):

Gregersen, I. B., Madsen, H., Rosbjerg, D., \& Arnbjerg-Nielsen, K. (2015). Long term variations of extreme rainfall in Denmark and southern Sweden. Climate Dynamics, 44(11-12), 3155-3169.

https://doi.org/10.1007/s00382-014-2276-4

\section{General rights}

Copyright and moral rights for the publications made accessible in the public portal are retained by the authors and/or other copyright owners and it is a condition of accessing publications that users recognise and abide by the legal requirements associated with these rights.

- Users may download and print one copy of any publication from the public portal for the purpose of private study or research.

- You may not further distribute the material or use it for any profit-making activity or commercial gain

- You may freely distribute the URL identifying the publication in the public portal

If you believe that this document breaches copyright please contact us providing details, and we will remove access to the work immediately and investigate your claim. 


\title{
Long term variations of extreme rainfall in Denmark and southern Sweden
}

\author{
Ida Bülow Gregersen · Henrik Madsen • Dan Rosbjerg • \\ Karsten Arnbjerg-Nielsen
}

Received: 5 February 2014 / Accepted: 22 July 2014 / Published online: 3 August 2014

(C) Springer-Verlag Berlin Heidelberg 2014

\begin{abstract}
A high number of studies have detected changes in the observed heavy rainfall in Northern and Central Europe, all adding to the debate on anthropogenic climate change and its potential impact on rainfall extremes. However, it is equally relevant to understand natural variations on which the anthropogenic changes are imposed. This study identifies multi-decadal variations in daily rainfall extremes from Denmark and southern Sweden, with a recurrence level relevant for flood hazard analysis. Based on smoothed series it is concluded that the frequency of the extreme events shows both a general increase from 1874 to present and an oscillation with a cycle of 25-40 years. The magnitude of the extreme events also oscillates, but with a cycle of 15-30 years and a smaller amplitude. Regional analysis of a larger Danish dataset with a shorter observations period found a countrywide low period in 1970-1979. It is furthermore concluded that the oscillation signal along the west coast of Denmark is dominated by the changeable coastal weather of this region. The eastern part of Denmark shows a more consistent signal, which partly can be explained by an index derived from sea level pressure differences between Gibraltar and Haparanda. The identification of a cyclic pattern in the extreme rainfall is highly relevant for our understanding of the non-stationarities in flood hazard.
\end{abstract}

Keywords Extreme rainfall $\cdot$ Multi-decadal oscillation · Natural variation $\cdot$ East Atlantic pattern

I. B. Gregersen $(\bowtie) \cdot$ D. Rosbjerg · K. Arnbjerg-Nielsen Department of Environmental Engineering, Technical University of Denmark, Miljoevej, Building 113, 2800 Kongens Lyngby,

Denmark

e-mail: idbg@env.dtu.dk

H. Madsen

DHI, Agern Alle 5, 2970 Hørsholm, Denmark

\section{Introduction}

The attention on climate change and its potential impacts on important hydrological variables has increased in recent years, especially with the frequent flooding of European cities within the last decade. In response, several studies have focused on the theoretical background for a shift in the occurrence and magnitude of heavy rainfall in a warmer climate (e.g., Fowler and Hennessy 1995; Lenderink and Meijgaard 2008; Trenberth et al. 2003), while others have investigated if the expected effect is already observable in the available rainfall records. Both Min et al. (2011) and Westra et al. (2013) concluded that a statistically significant increase in the annual maximum daily precipitation can be detected on a global basis. For Northern and Central Europe a number of recent studies exists for various regions; Belgium (Ntegeka and Willems 2008), Czech Republic (Kysely 2009), Denmark (Gregersen et al. 2013a), Germany/Poland (Lupikasza et al. 2011), Sweden (Bengtsson and Rana 2013) and UK (Rodda et al. 2010). Depending on season, region within the country and analysed indices, they all detect changes in heavy rainfall. However, as several of the authors argue, the observed change cannot easily be linked directly to climatic changes. Another aspect is that the magnitude and statistical significance of a trend can be very sensitive with respect to the length of data series and the analysed period (Bengtsson and Rana 2013; Ntegeka and Willems 2008).

The study of natural multi- and inter-decadal variations in different climatic variables is comprehensive. Many authors have studied the link between regional climate and the various teleconnections, represented as indices of Sea Surface Temperature (SST) and Sea Level Pressure (SLP). Dai (2013) and Enfield et al. (2001) linked multi-decadal changes in the precipitation over US to an oscillation 
pattern in the SST of the Pacific and North Atlantic Ocean. In relation to variations of extreme winter and autumn precipitation in Europe several authors have found a link to the North Atlantic Oscillation (NAO) index (e.g. Heikkila and Sorteberg 2012; Scaife et al. 2008), which is estimated from SLP differences (SLPD) between the Azores and Iceland. Willems (2013) concluded that a higher degree of explanation is obtained if the index is estimated from SLPD between Gibraltar and Scandinavia. Gregersen et al. (2013a) found a correlation between the frequency of heavy rainfall events and the East Atlantic (EA) pattern, which is the second most prominent mode of SLP variability over the North Atlantic (NOAA 2013b).

Fewer studies have focused specifically on the multidecadal variations in rainfall extremes. Ntegeka and Willems (2008) analysed temporal patterns of anomalies of Peak over Threshold (POT) extremes and identified oscillation patterns in the rainfall extremes of a 107-year time series from Belgium. Willems (2013) extended the analysis and confirmed that the oscillation period is $35-40$ years and consistent for different seasons and rainfall durations (10 min to 1 month). Willems (2013) also documented that the multi-decadal variations of the 15 highest daily rainfall events in the winter season show a consistent pattern over Europe, with similar oscillation periods but a phase shift depending on the region. The present paper is inspired by these findings and aims to study multi-decadal variations of extreme rainfall in Denmark and southern Sweden using six 137-year long series of daily rainfall, together with 61 series with $45-100$ years of measurements. The purpose is to investigate the regional consistency of the multidecadal variation for rainfall extremes occurring with a frequency relevant for flood hazard analysis in a Danish context. By use of the POT framework we model variations in the frequency and magnitude of extreme rainfall separately, as this has been found advantageous in regional analysis of extreme rainfall (e.g. Madsen et al. 2002). Furthermore, the link between the two indices and various teleconnections is investigated.

\section{Methods}

\subsection{Perturbation factors for extreme rainfall}

The POT method is applied to define a Partial Duration Series (PDS) of the extreme rain events (Coles 2001; Madsen et al. 1997) from a time series of daily rainfalls. From this the annual frequency $(\lambda)$ and annual mean magnitude $(\mu)$ of extreme events are estimated. A dry weather period of one day is required for two succeeding events to be considered as independent (Gregersen et al. 2013b; Madsen et al. 2002). For consistency with previous Danish studies
(Gregersen et al. 2013b; Madsen et al. 2002) we apply a threshold which yields approximately three extreme events per year in the standard normal period of 1961-1990.

Due to the highly variable nature of rainfall extremes it can be difficult to separate long term trends from random variations, when the evaluations are made on an annual basis. Ntegeka and Willems (2008) successfully applied a moving window of 5-15 years as a filter to enhance the multidecadal signal for extreme rainfall variations. The filter can be expressed as a perturbation factor $(p f)$ where a selected extreme value characteristic $\left(C_{\text {extreme }}\right)$ is calculated for both the subseries $\left(t_{\text {sub }}\right)$, defined by the moving window, and the full series $\left(t_{f u l l}\right)$ :

$p f=\frac{C_{\text {extreme }}\left(t_{\text {sub }}\right)}{C_{\text {extreme }}\left(t_{\text {full }}\right)}$

A $p f$ estimated for the average annual number of events is denoted $p f_{\lambda}$, while a $p f$ estimated for the mean extreme intensity events is denoted $p f_{\mu}$. The method requires an observation period of several decades. A perturbation factor of 1.3 indicates that the anomaly of the corresponding subperiod is $30 \%$ above the average. The length of the moving window is 10 years in all calculations unless another value is stated explicitly, meaning that the generated series of perturbation factors are highly auto-correlated. To ensure that the multi-decadal variations of the perturbation factors are not artefacts generated by the rectangular moving window, different window lengths are tested using also a weighted Bartlett and a weighted exponential window. The spectral analysis described below is also performed for the unsmoothed series of and $\lambda$ and $\mu$.

In contrast to the procedure described above Ntegeka and Willems (2008) estimate perturbation factors from the extreme quantiles of $t_{f u l l}$ and $t_{s u b}$, doing so the contribution from changes in frequency of the events and the magnitude of the events is analysed as one common perturbation factor.

\subsection{Modelling oscillations and trends}

Spectral analysis, in its many forms, is commonly applied for evaluation of cyclic patterns. We apply a Fast Fourier Transformation (FFT) (Shumway and Stoffer 2010) to the $\lambda, \mu, p f_{\lambda}$ and $p f_{\mu}$ series and evaluate plots of the spectral densities, to see if observations occurring at specific frequencies are more correlated than others. If so, they will appear as well-defined peaks, and the period of the oscillations can be estimated directly from the periodogram. Linear trends in the time series are eliminated as they otherwise disturb the interpretation of the periodogram. Furthermore, the periodogram is often smoothed to reduce uncertainty and thereby allow for a better evaluation of the important peaks (Shumway and Stoffer 2010). The applied 
smoothing length reflects the number of merged frequencies. Approximate confidence levels for the primary peak can be estimated under the assumption of a $\chi^{2}$-distribution and depend on the level of smoothing. This level defines a baseline below which the individual peaks cannot be distinguished from each other (Shumway and Stoffer 2010). As multi-decadal variations are the focus of the study, the scale of the periodogram is not transformed to $\log _{10}$, which otherwise is recommended to highlight high-frequency patterns.

If a cyclic pattern is confirmed by the spectral analysis, a periodic sine function can be fitted by use of a non-linear least-squares (NLLS) procedure. Allowing for a mixture of a linear trend and a sine oscillation the parameters in the following relationship is estimated

$p f=a+($ time -1942$)+c \sin \left(2 \pi \frac{\left(\text { time }-t_{0}\right)}{d}\right)$

where $a$ is the intercept, $b$ the linear slope, $c$ the amplitude, $d$ the period and $t_{0}$ the phase. To normalize the independent variable time, measured in years, a value of 1942 is subtracted. The choice of this arbitrary value depends on the period of observation. Model evaluation is performed by the Akaike Information Criterion (AIC). The AIC index of the sine model is compared to the AIC index of a linear model where the oscillation term is omitted. Of two competing models the one with the lowest AIC value is preferred. Note that the model residuals are heavily auto-correlated due to the moving window procedure; this affects the significance of the modelled parameters as the degrees of freedom in the dataset are falsely high. Conclusions regarding the significance of the periodic behaviour should therefore not only be based on the AIC.

All calculations are performed in the statistical language $\mathrm{R}$ using the functions FFT and NLLS within the basic statspackage (R Core Team 2012). Furthermore, the package ggplot2 (Wickham 2009) has been applied for graphics.

\section{Data and study area}

The main study area is Denmark and the very southern part of Sweden, see Fig. 1. Denmark is located on the border between the North Sea and the European Continent. This provides for a mild coastal climate which in Western Jutland is particularly changeable. The predominant wind direction is from west to east which, depending on the storm tracks and the location of the Polar Jet Stream, brings frontal depression systems from the North Sea towards Denmark (Cappelen 2013). A ridge through
Fig. 1 The location of the analysed rain gauge stations in Denmark and southern Sweden. Danish stations are marked with circles. Swedish stations are marked with triangles. All stations have at least 45 years of continuous measurements. The six stations with long records of more than 137 years are highlighted

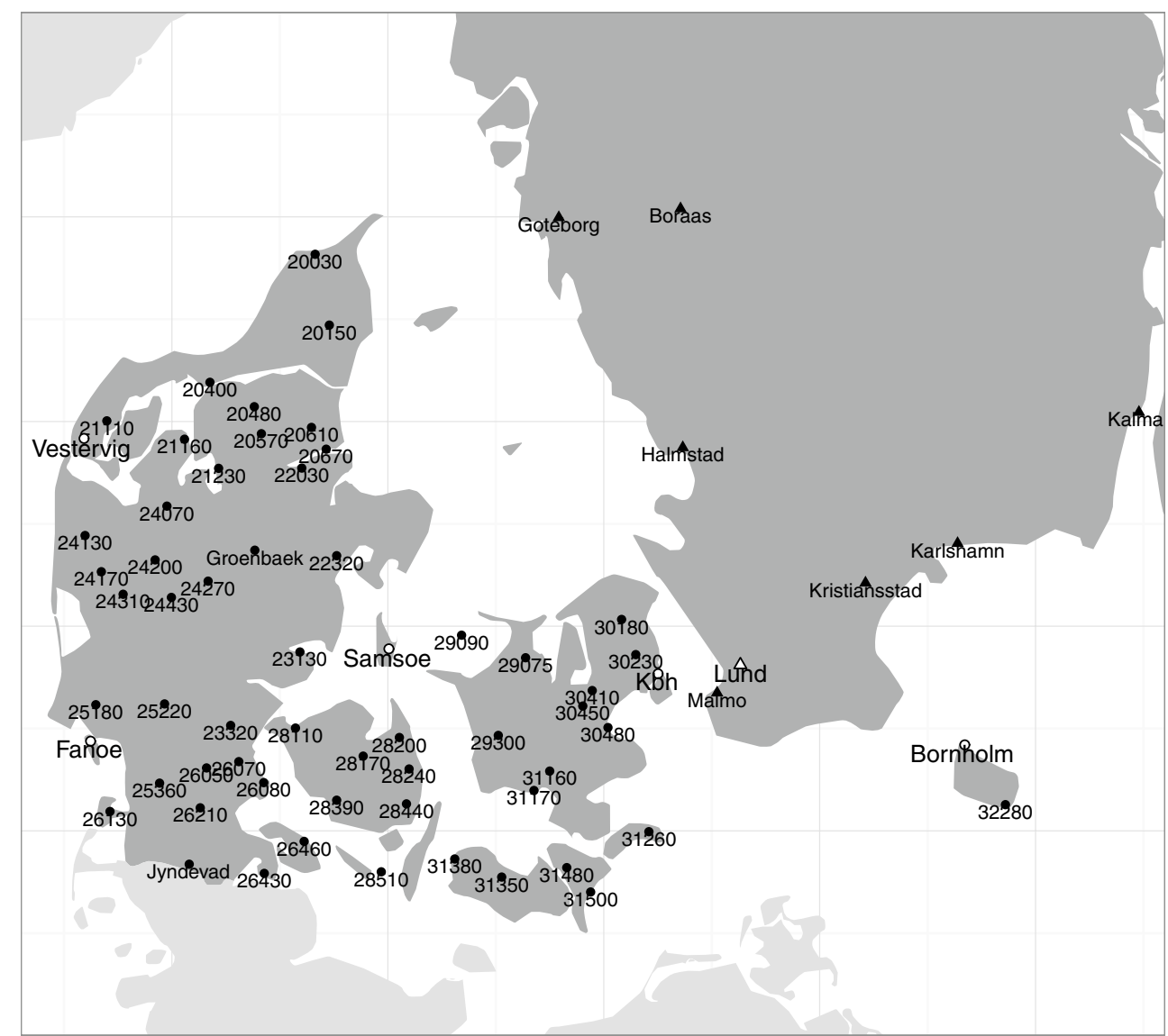


Jutland formed during the late Ice age produces an orographic effect that affects the regional variation of annual precipitation (Frich et al. 1997). Depending on the storm track direction it is plausible that rainfall patterns in the most northern part of Jutland is influenced by the shelter from Norway. The climate in the most eastern part of Denmark and the southern part of Sweden resembles more the climate of the continent. A southern or eastern wind direction will bring air from the continent, which in combination with the warm waters from the Baltic Sea can create good conditions for thunderstorms and convective showers (Cappelen 2013; Frich et al. 1997). In relation to the regional variation of rainfall extremes Madsen et al. (2002) showed that the frequency of the extreme events can be correlated to the regional variation of the mean annual precipitation, whereas regional differences also exist for the magnitudes.

Long series of observed daily rainfall are available from five manual Hellman rain gauge stations maintained by the Danish Meteorological Institute. The registration of accumulated diurnal precipitation is made each morning. The observation period is 137 years, from 1874 to 2010, and the resolution is $0.1 \mathrm{~mm} /$ day. The geographical location and the name of the stations appear from Fig. 1. Only two of the five series (Fanoe and Vestervig) originate from a rain gauge, which has been located at the exact same location during the entire period of measurement. The rain gauge at Samsoe was relocated in 2001, whereas the series for Bornholm and Copenhagen (Kbh) are assembled by measurements from two and three geographically close stations, respectively. The assembling is performed by a random selection between the overlapping measurements. It has been verified that the concurrent measurements are very alike and that several realizations of the selection procedure lead to almost identical series of perturbation factors. Furthermore, the homogeneity of all five series has been confirmed by double mass curves (Dingman 1994). The five final series do have days with missing measurements. In relation to the independence criteria days with missing measurements count as dry days. For the five series the number of days with missing measurements constitutes at a maximum $2.5 \%$ of the total series and the few consecutive periods with missing measurements are no longer than 2 months.

As a supplement, two series with daily measurements starting in 1911 and 1920, respectively, together with 54 series from the period 1961-2010 are also available from the Danish Meteorological Institute (Lundholm and Cappelen 2011), see Fig. 1. More station records exist but they were discarded by a homogeneity test comparing the observed accumulated precipitation and interpolated accumulated precipitation from surrounding stations (Lundholm and Cappelen 2010). The rain gauge type and the registration procedures are as described above. The length of the series differs, but all have at least 45 years of continuous observation.
For seven locations in southern Sweden measurements of daily rainfall are available from the Swedish Meteorological and Hydrological Institute, see Fig. 1. The observation period ranges from 1873 to 2010, and the resolution is $0.1 \mathrm{~mm} /$ day. Not all stations have measurements in the entire period. Daily measurements are in particular missing from 1931 to 1961 , where only annual precipitation and monthly maxima have been registered for many of the stations. In other, shorter periods, only information on rain events above $10 \mathrm{~mm}$ is available. The station in Lund has 138 years of continuous measurements. For all other stations periods with more than 45 years of continuous measurements are extracted from the full series and used in the analysis. The registration procedures have furthermore been altered during the period of measurement, from registration of 'precipitation' and 'no precipitation', to distinguishing between both 'precipitation', 'little precipitation' and 'no precipitation'. In relation to the independence criteria both days with 'little precipitation' and 'no precipitation' count as dry days.

In light of the results from the existing literature the link between temporal rainfall variations and various teleconnections are explored with focus on SLP and SST. Regarding SST both the Atlantic Multi-decadal Oscillation (AMO) index (NOAA 2013a) presented by Enfield et al. (2001) and more local SST for the North Sea (along the coast of Jutland) and the Baltic Sea (between Bornholm and Zealand) extracted from the HADISST1 dataset (Hadley Centre 2013; Rayner et al. 2003) are available. Regarding SLP local series of mean monthly SLP (in mbar) are published by Cappelen (2013) for the location of the five long Danish rainfall series (see Fig. 1). The series are estimated from sub-daily measurements, which are corrected throughout the measurement period to obtain uniform estimates of the pressure at sea level. Furthermore, monthly SLP observations (in mbar) are available from Gibraltar (Spain) and Haparanda (Sweden) (Jones et al. 1999). Using the series from Gibraltar normalized pressure differences can be estimated between this station and all the six Scandinavian SLP series, as a proxy for the EA index. More robust estimates of the SLP indices are achieved by a Principal Component analysis of gridded re-analysis data; however these are only available from NOAA (2013b) from 1950. CRU (2013) provides a station-based NAO index from 1821.

\section{Results}

4.1 Multi-decadal variations over 137 years of measurements

$p f_{\lambda}$ series are estimated for the six stations with more than 137 years of measurements. At least three of the six 


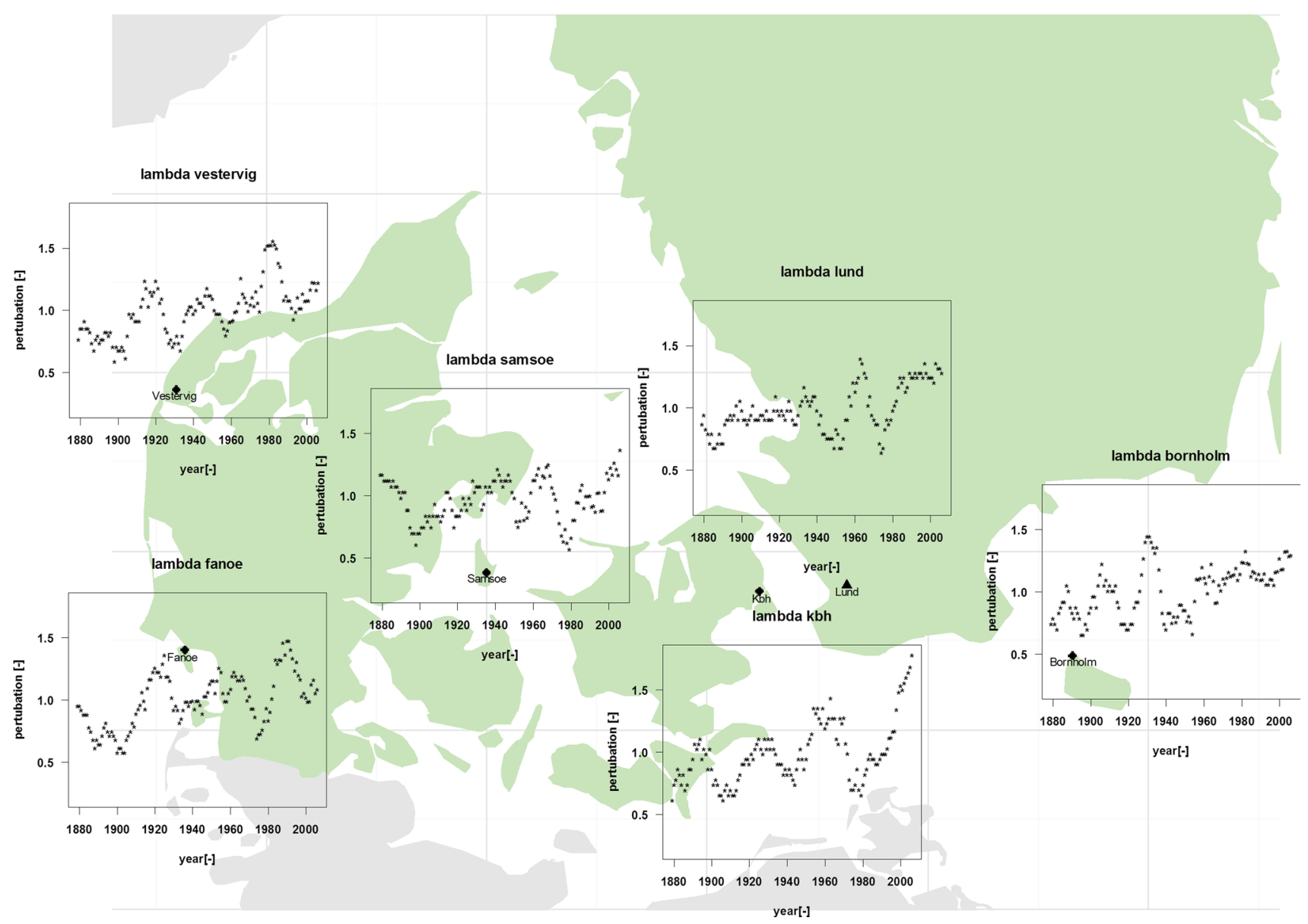

Fig. 2 Multi-decadal variation in the frequency of extreme events. Over 137 years of measurements for six stations in Denmark and southern Sweden

$p f_{\lambda}$ curves (Vestervig, Fanoe and Kbh) show an oscillating behaviour, see Fig. 2. The pattern is confirmed by a comparison with the unsmoothed $\lambda$ series and by applying different types and lengths of the moving average window. The spectral densities are estimated for the $\lambda$ and the $p f_{\lambda}$ series, respectively, see Fig. 3. The periodograms of the six $p f_{\lambda}$ series clearly shows a signal from a periodic pattern with a period of 25-35 years, except for Samsoe where the period is longer. In comparison, the periodograms for the unsmoothed $\lambda$ series also show peaks with higher frequencies representing the total variability of $\lambda$, see Fig. 3. These are not present in the $p f_{\lambda}$ series due to the smoothing procedure. However, the signal from a periodic pattern with a period of 25-35 years is distinguishable from the baseline for all stations except Samsoe and for Kbh it is the dominating peak. There is some variation in the estimated periods between stations and the peaks of the $p f_{\lambda}$ are not pure spikes, which together indicate, that the cycle is slightly irregular. The conclusions from the spectral analysis of $\lambda$ and the $p f_{\lambda}$ series is summarized in Table 1. $p f_{\mu}$ series are also estimated for the six stations, see Fig. 4. Weak oscillation patterns are found for this variable as well. For four out of the six stations the period of the pattern is approximately 20 years. However, the spectral analysis of the six $\mu$ and $p f_{\mu}$ series shows that the signal enhanced by the moving average window is vague for the unsmoothed $\mu$ series, see Fig. 5. Looking at the smoothed periodograms for series of $\mu$ it is seen that for Vestervig, Fanoe and Samsoe the peaks, which represent the multidecadal signal, are barely distinguishable from the baseline. While for Kbh, Lund and Bornholm there are dual peaks, which for the two first stations are too close to be clearly distinguished from each other. The conclusions from the spectral analysis of $\mu$ and the $p f_{\mu}$ series are summarized in Table 1.

The initial analysis of the $p f_{\lambda}$ series and $p f_{\mu}$ series shows that oscillating patterns can be identified for both $\lambda$ and $\mu$, however of a rather different nature. The variation of the $p f_{\lambda}$ has, in general, both higher amplitude and a longer period, in comparison to the variation of the $p f_{\mu}$, see Figs. 2, 4; Table 1 . Both variables show regional differences. For $p f_{\lambda}$ 
Fig. 3 Estimated spectral density for the six linearly detrended series of $\lambda$ (left column) and the six linearly de-trended series of $p f_{\lambda}$ (right column). Each plot includes a raw and a smoothed periodogram, for the latter the applied smoothing length is three. The period of the maximum peak of the $p f_{\lambda}$ series (right column) is given in years, the corresponding peak in the $\lambda$ series is marked by red arrows (left column). The horizontal line in the smoothed periodogram represents the lower $95 \%$-confidence interval of the maximum peak
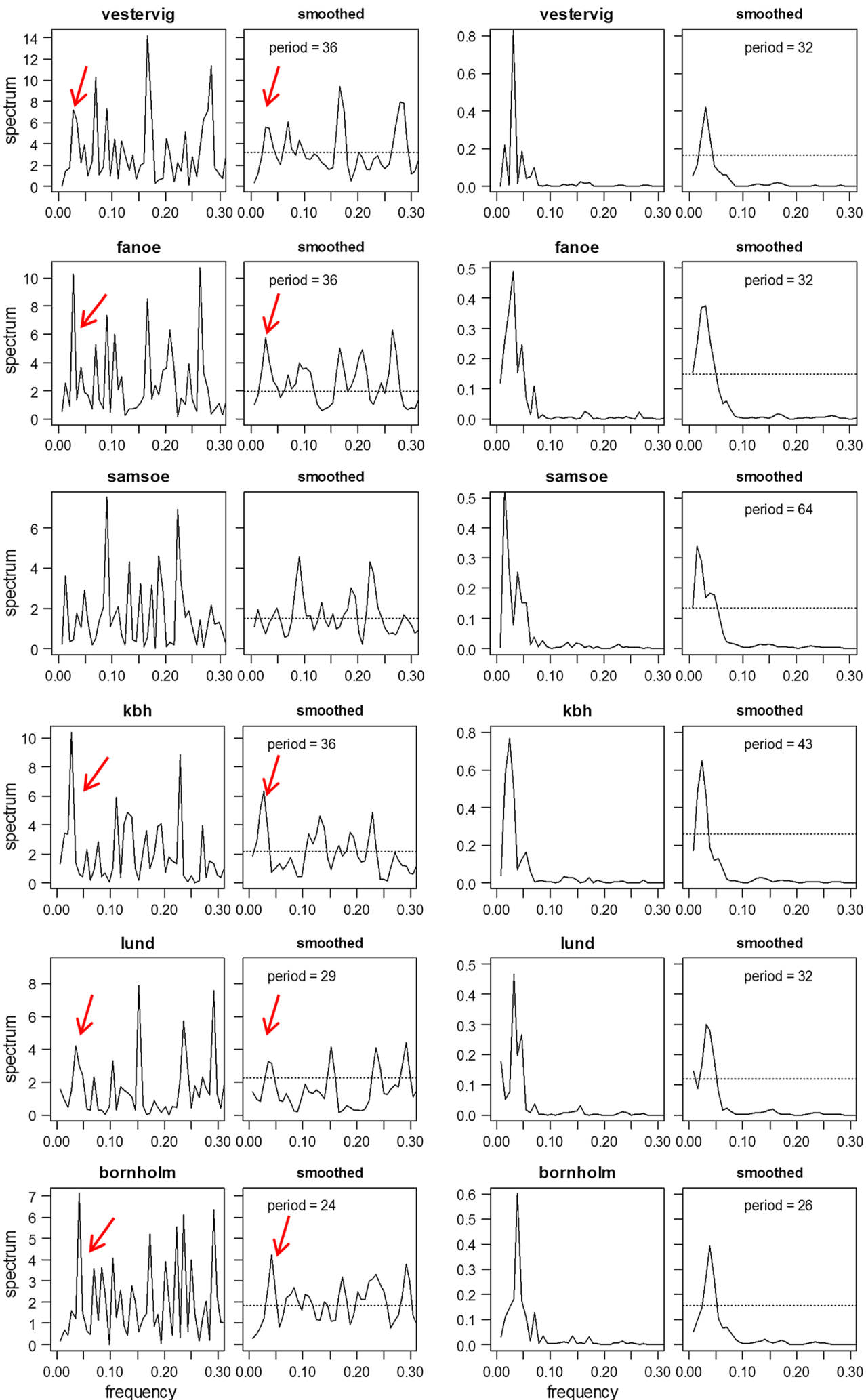

there seems to be a phase shift in the oscillations going from the western to the eastern part of Denmark. For $\mu$ the smoothed periodograms for the eastern and western stations show some similarities. The period of variation in $\lambda$ and $\mu$ are more similar for Kbh, Lund and Bornholm, than for Vestervig and Fanoe. This indicates that the same large scale driver might dominate the temporal variability of $\lambda$ and $\mu$ in the eastern part of Denmark but not in the western 
Table 1 The periods of the major peaks in the smoothed periodograms of the $\lambda, p f_{\lambda}, \mu$ and $p f_{\mu}$ series

\begin{tabular}{lllll}
\hline Station & Period of $\lambda$ oscillations [years] & Period of $p f_{\lambda}$ oscillations [years] & Period of $\mu$ oscillations [years] & Period of $p f_{\mu}$ oscillations [years] \\
\hline Vestervig & $\mathbf{3 6}$ & $\mathbf{3 2}$ & 18 & $\mathbf{1 8}$ \\
Fanoe & $\mathbf{3 6}$ & $\mathbf{3 2}$ & $\mathbf{1 8}$ & 16 \\
Samsoe & 72 & $\mathbf{6 4}$ & 48 & $\mathbf{4 3}$ \\
Kbh & $\mathbf{3 6}$ & $\mathbf{4 3}$ & $\mathbf{3 6}$ & $\mathbf{3 2}$ \\
Lund & $\mathbf{2 9}$ & $\mathbf{3 2}$ & $\mathbf{2 1}$ & $\mathbf{2 1}$ \\
Bornholm & $\mathbf{2 4}$ & $\mathbf{2 6}$ & $\mathbf{2 4}$ & $\mathbf{6 4}(\mathbf{2 1})$ \\
\hline
\end{tabular}

Bold values indicate that the peak is distinctive above the lower $95 \%$-confidence limit using a smoothing length of three

Values given in parenthesis indicates that more than one peak is distinctive above the lower $95 \%$-confidence limit

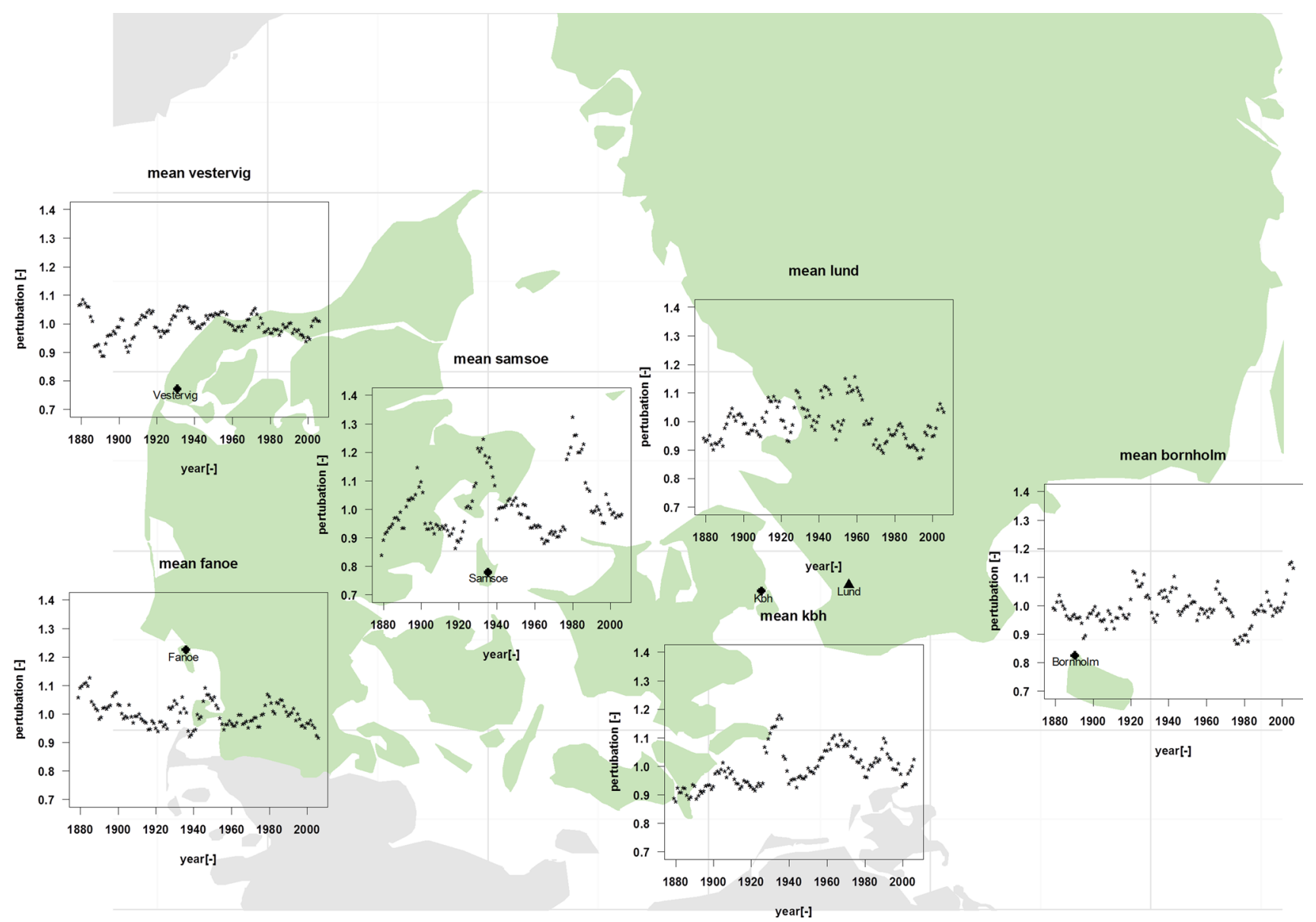

Fig. 4 Multi-decadal variation in the mean magnitude of extreme events. Over 137 years of measurements for six stations in Denmark and southern Sweden

part. The regional variations and the link to large scale drivers are studied further in Sect. 4.2 and 4.3, respectively.

A model with an oscillation component is fitted to the six $p f_{\lambda}$ series, see Eq. (1). The estimated parameters are given in Table 2. For comparison of AIC values an ordinary linear model (Eq. (1) with $c=0$ ) is also fitted to the $p f_{\lambda}$ series. For all six stations the oscillation model provides a better fit to the data than the linear model. However, for all six stations the linear slope in Eq. (1) is found to be significant and positive, indicating that the series in addition to the oscillating behaviour show an increase over time. Comparing the estimated period of Eq. (1) with the estimate from the spectral analysis, see Table 1, the two are not identical; this reflects the uncertainty within the estimation procedures. The difference is highest for Samsoe, which is also the station where the cyclic pattern is less identifiable, 
Fig. 5 Estimated spectral density for the six linearly detrended series of $\mu$ (left column) and the six linearly de-trended series of $p f_{\mu}($ right column). Each plot includes a raw and a smoothed periodogram, for the latter the applied smoothing length is three. The period of the maximum peak of the $p f_{\mu}$ series (right column) is given in years, the corresponding peak in the $\mu$ series is marked by red arrows (left column). The horizontal line in the smoothed periodogram represents the lower $95 \%$-confidence interval of the maximum peak
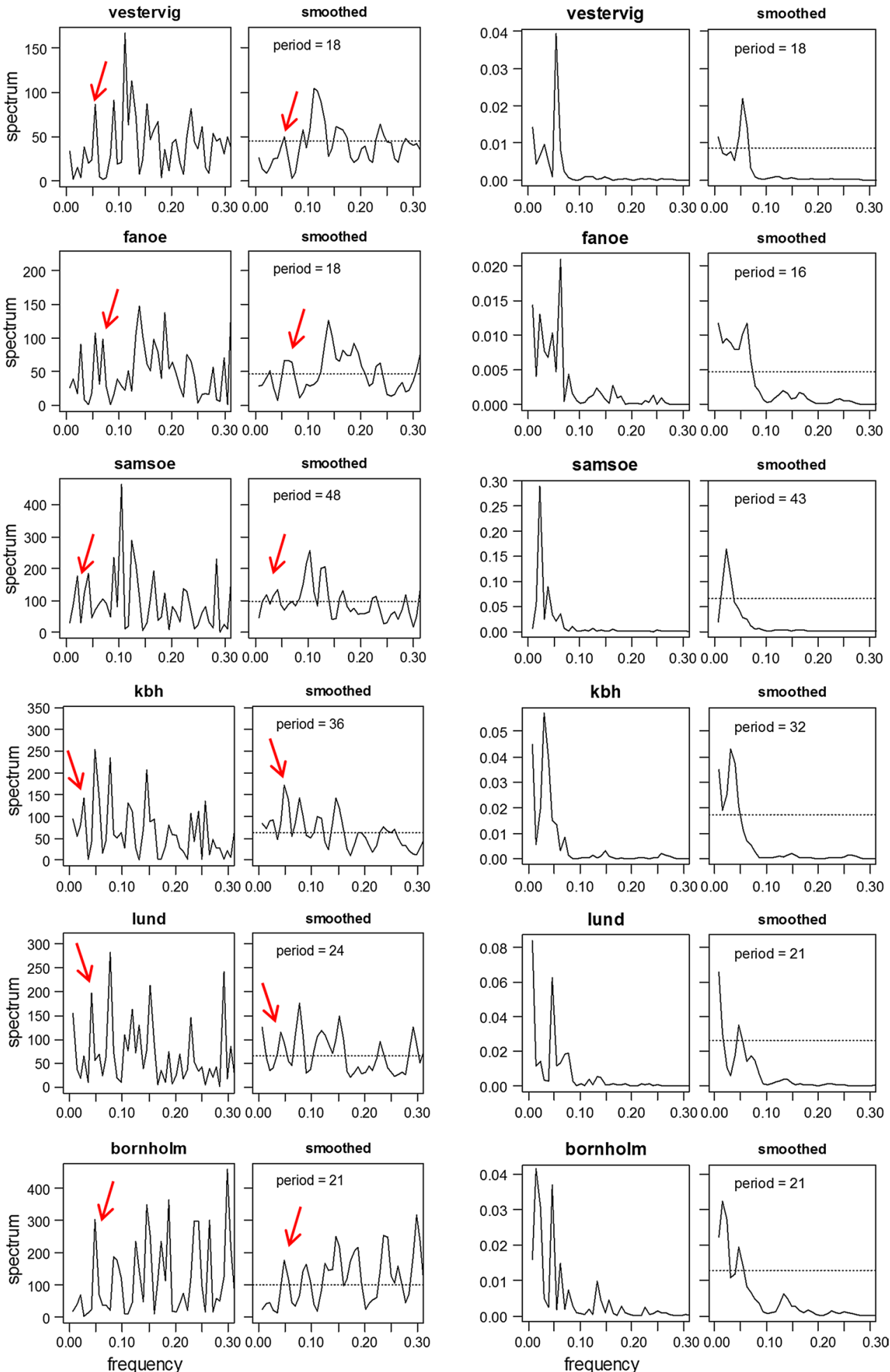

see Fig. 2. The uncertainty of the estimated parameters, reflected by the standard deviation, is also highest for this station. The Kbh station has, in terms of a relatively high AIC value, the least optimal fit of the sine model to the observations. Even though the oscillation behaviour is quite clear for this station, see Fig. 2, the fitted sine model is constrained by the assumption of a constant period and amplitude. Visual inspection of the oscillations suggests that both amplitude and period are increasing over time for the Kbh station, but with only three full cycles within the observation period this pattern cannot be confirmed by statistical means. 
Table 2 The oscillation model for $p f_{\lambda}$

\begin{tabular}{|c|c|c|c|c|c|c|c|}
\hline & $\begin{array}{l}\text { Intercept } \\
\mathrm{a}\end{array}$ & $\begin{array}{l}\text { Increase } \\
\mathrm{b}\end{array}$ & $\begin{array}{l}\text { Amplitude } \\
\text { c }\end{array}$ & $\begin{array}{l}\text { Period } \\
\text { d }\end{array}$ & $\begin{array}{l}\text { Phase } \\
t_{0}\end{array}$ & $\mathrm{AIC}_{\mathrm{sin}}$ & $\mathrm{AIC}_{\text {linear }}$ \\
\hline Vestervig & $1.00(0.01)$ & $0.004(0.0003)$ & $0.17(0.01)$ & $32.6(0.4)$ & 1907 (0.6) & -190.9 & -100.4 \\
\hline Fanoe & $0.99(0.01)$ & $0.003(0.0003)$ & $0.17(0.02)$ & $36.3(0.6)$ & $1910(0.8)$ & -153.8 & -75.0 \\
\hline Samsoe & $0.99(0.01)$ & $0.001(0.0004)$ & $0.14(0.02)$ & $69.5(2.4)$ & $1926(1.5)$ & -142.1 & -92.8 \\
\hline Kbh & $0.97(0.01)$ & $0.004(0.0003)$ & $0.22(0.02)$ & $36.7(0.5)$ & $1917(0.6)$ & -136.0 & -37.7 \\
\hline Bornholm & $1.00(0.01)$ & $0.003(0.0003)$ & $0.14(0.02)$ & $24.5(0.3)$ & $1902(0.7)$ & -146.5 & -91.1 \\
\hline Lund & $0.99(0.01)$ & $0.003(0.0003)$ & $0.13(0.02)$ & $30.7(0.5)$ & $1923(0.7)$ & -163.1 & -114.7 \\
\hline
\end{tabular}

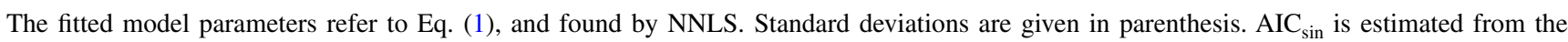
model given by Eq. (1), while $\mathrm{AIC}_{\text {linear }}$ is estimated from the model given by Eq. (1) with $\mathrm{c}=0$

Table 3 The oscillation model for $p f_{\mu}$

\begin{tabular}{|c|c|c|c|c|c|c|c|}
\hline & $\begin{array}{l}\text { Intercept } \\
\mathrm{a}\end{array}$ & $\begin{array}{l}\text { Increase } \\
\mathrm{b}\end{array}$ & $\begin{array}{l}\text { Amplitude } \\
\text { c }\end{array}$ & $\begin{array}{l}\text { Period } \\
\text { d }\end{array}$ & $\begin{array}{l}\text { Phase } \\
\mathrm{t}_{0}\end{array}$ & $\mathrm{AIC}_{\text {sin }}$ & $\mathrm{AIC}_{\text {linear }}$ \\
\hline Vestervig & $1.00(0.003)$ & - & $0.04(0.004)$ & $18.1(0.2)$ & $1912(0.43)$ & -513.9 & -456.0 \\
\hline Samsoe & $1.00(0.006)$ & $0.0009(0.0002)$ & $0.1(0.009)$ & $44.1(0.8)$ & $1927(0.7)$ & -305.7 & -224.5 \\
\hline Kbh & $1.00(0.005)$ & $0.0009(0.0001)$ & $0.05(0.006)$ & $29.0(0.4)$ & $1926(0.6)$ & -407.4 & -353.0 \\
\hline Bornholm & $0.99(0.005)$ & - & $0.03(0.005)$ & $21.0(0.4)$ & $1918(0.8)$ & -387.5 & -368.3 \\
\hline Bornholm & $1.00(0.004)$ & - & $0.05(0.006)$ & $76.3(2.7)$ & 1918 (1.6) & -419.7 & -368.3 \\
\hline Lund & $1.00(0.005)$ & - & $0.05(0.007)$ & $22.0(0.3)$ & 1977 (0.8) & -356.5 & -328.0 \\
\hline
\end{tabular}

The fitted model parameters refer to Eq. (1), and found by NNLS. Standard deviations are given in parenthesis. AIC sin $_{\text {is }}$ estimated from the model given by Eq. (1), with the parameters as given in the preceding columns. Parameter values replaced by "- indicate that the parameter was found non-significant by a $t$ test. $\mathrm{AIC}_{\text {linear }}$ is estimated from the model given by Eq. (1) with $\mathrm{c}=0$

Sine models are fitted to the six $p f_{\mu}$ series in a similar manner. Fanoe is excluded from this analysis because the oscillation is weak for this station, see Table 1 . The estimated parameters are given in Table 3. It is seen that the amplitude is remarkably smaller than for $p f_{\lambda}$, still the AIC index suggests that the sine component is an important part of the model. For Bornholm a model with a longer period (76 years) is found to explain a higher degree of the variation in the data, than a model with a shorter period (21 years). This is in accordance with the relative importance of the peaks in the periodogram, see Table 1. Only for Samsoe and Kbh do the mean intensities, in addition to the oscillating behaviour, show an increase over time.

\subsection{Regional oscillation patterns}

As mentioned earlier, Fig. 2 gives an important indication of regional variability of $\lambda$. For the $p f_{\lambda}$ series with the most pronounced oscillations one notices a phase shift. For the two stations along the west coast periods with high/low values occur almost simultaneously in the beginning of the observation period, but the phase difference increases with time and the most recent oscillation peak occur approximately 10 years later at Fanoe, see Fig. 6. The oscillations at Vestervig and Kbh have almost opposite phases, see Fig. 6. The $p f_{\lambda}$ series for Kbh has a peak in the 1960'ties, a similar tendency is found for the station in Lund, see Fig. 2. If the oscillation patterns are different for the western and eastern part of Denmark, the blurred signal for Samsoe could be caused by a mixture of the two.

The regional variability of $p f_{\lambda}$ and $p f_{\mu}$ are explored using the supplementary data from the 56 Danish and six Swedish stations. First, oscillation models cf. Eq. (1) are fitted to all $p f_{\lambda}$ series. For a selection of plots which represent the different parts of Denmark and southern Sweden, see Fig. 7. Some of the stations have only 45 years of measurements, which corresponds to one or two oscillation cycles, and this can obviously affect the parameter estimation. Comparisons were made between the long series and nearby stations, showing a general consistency in the oscillation signal during the period with overlapping measurements. However, strong conclusions cannot be drawn regarding the regional displacement. The amplitude of the oscillations is high along the west coast of Denmark, but there is a lack of concurrency between high/low periods, see Fig. 6 . In the Central part of Denmark, the amplitude of the oscillations is smaller, and for a few stations the AIC index was found to be in favour of a linear model. In the eastern part 

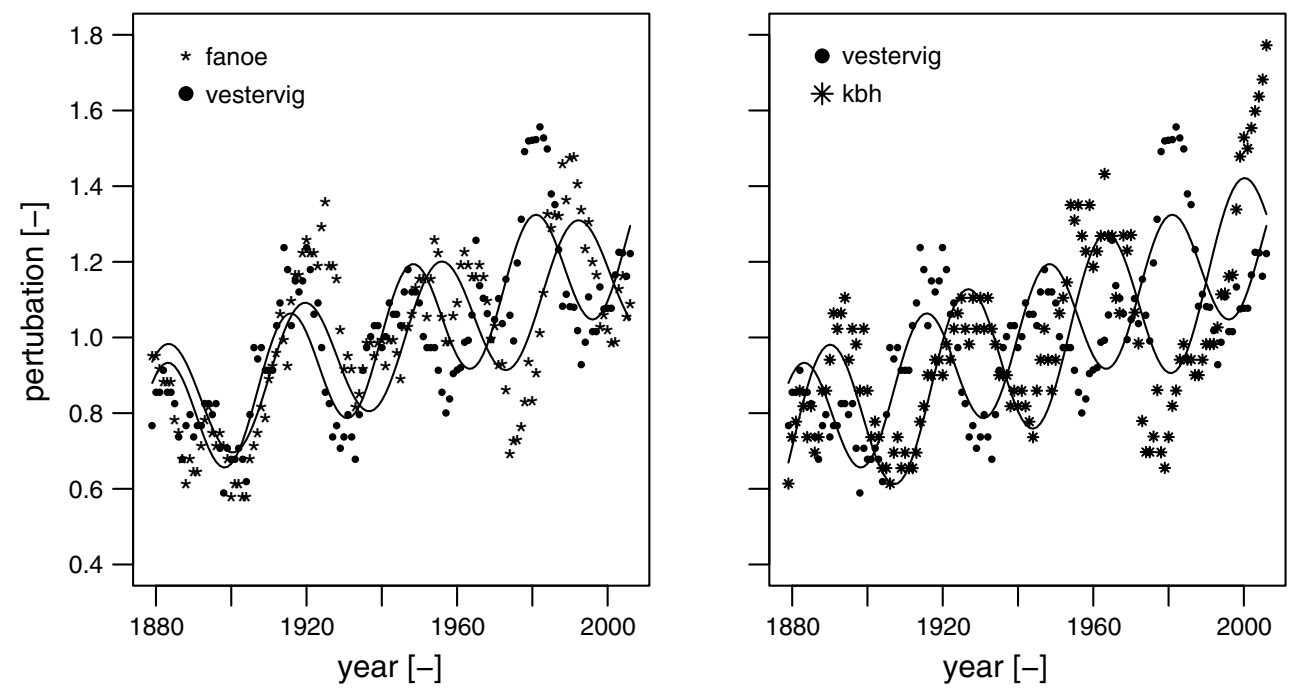

Fig. 6 Regional phase shift in the $p f_{\lambda}$ oscillations based on observations from Fanoe, Vestervig and Kbh

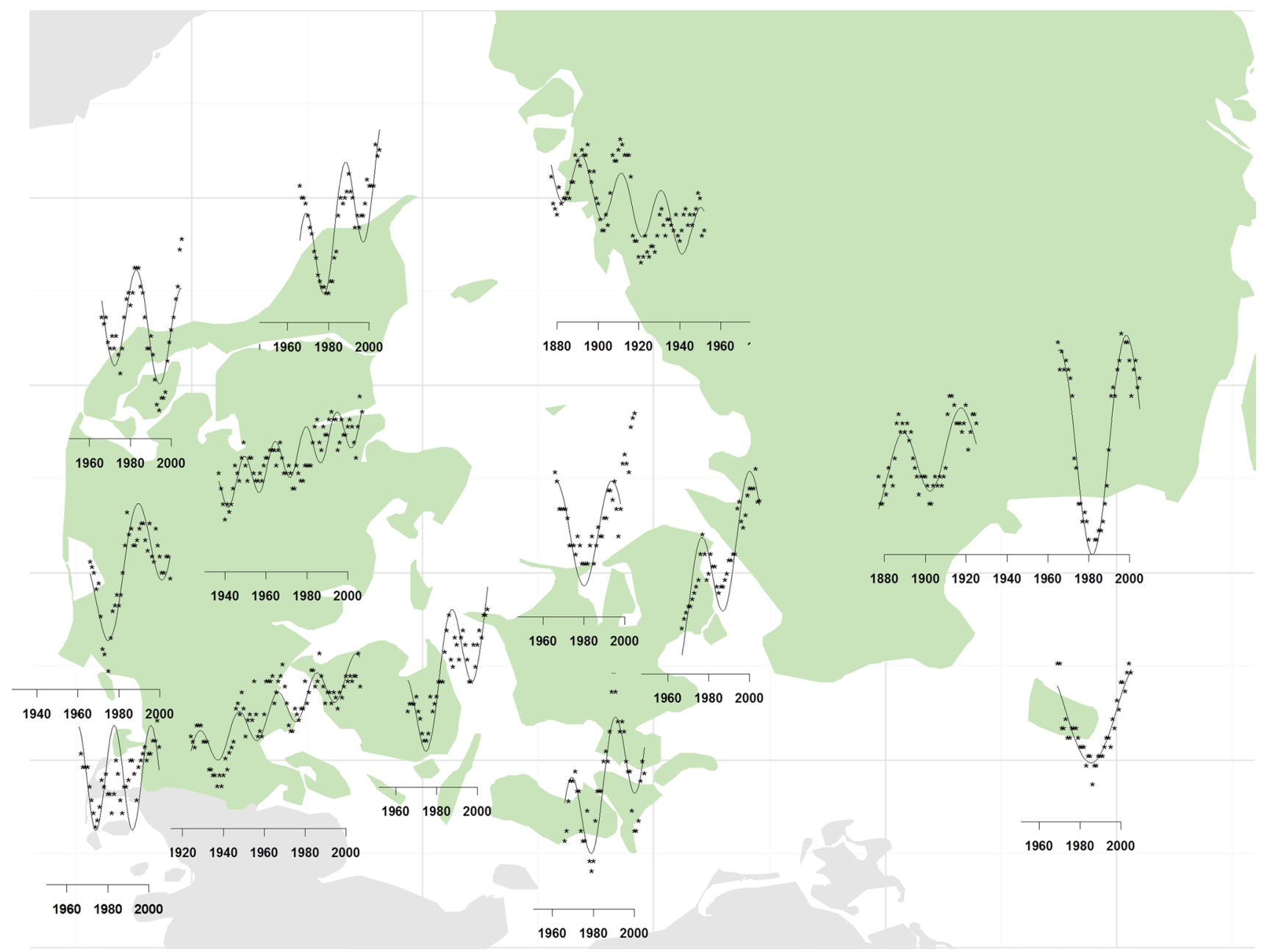

Fig. 7 Regional variability of $p_{f \lambda}$ represented by selected stations with at least 45 years of measurements. The scale of the perturbation is $0.5-$ 1.5 for all stations 
Fig. 8 Annual box-plots of the $p f_{\lambda}$ based on data from 1961 to 2009 and a all 67 stations b all stations in Fuen and Zealand, with the Kbh stations highlighted as a red line $\mathbf{c}$ all stations in Jutland, with the Fanoe and Vestervig stations highlighted as a red and blue line, respectively

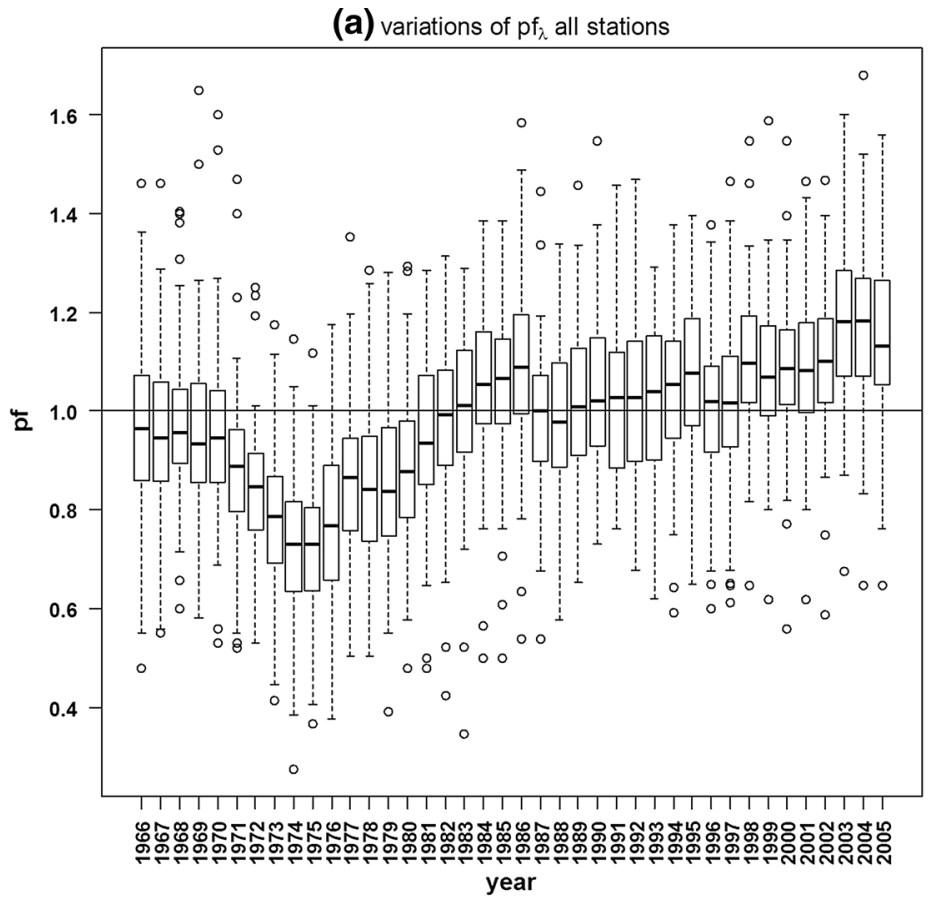

(b) variations of $\mathrm{pf}_{\lambda}$ Zealand and Fuen

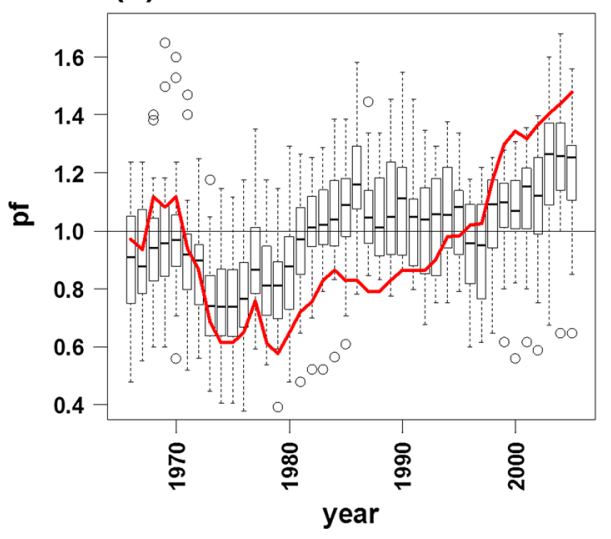

(c) variations of $\mathrm{pf}_{\lambda}$ Jutland

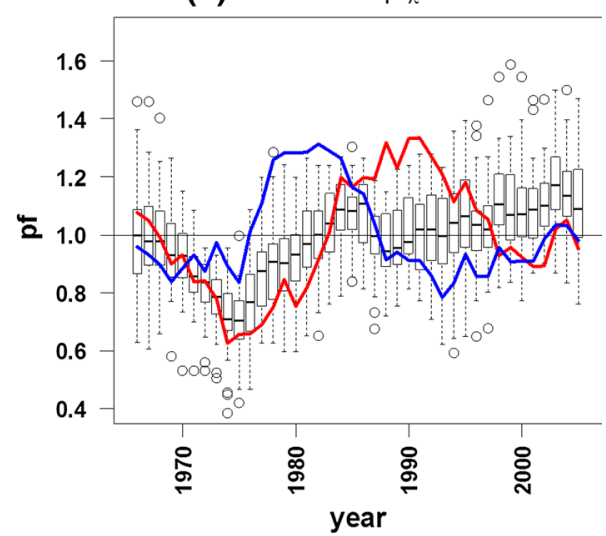

of Denmark and southern part of Sweden the amplitude of the oscillations increases again, and here we see a better agreement between high/low periods (e.g. the low around 1980). The station in Goteborg shows, in addition to the oscillations, a general linear decrease. A similar tendency was found for some of the Danish stations. As there is no regional pattern in the sign or magnitude of the linear trend, it is assumed to be driven by local micro-climatic changes. Annual box-plots of the $p f_{\lambda}$ from all stations are computed to identify common trends that cover the entire region, see Fig. 8a. The figure shows that the regional variability is generally high, but that the period 1970-1979 has a low $p f_{\lambda}$ throughout the region. The analysis by Willems (2013) also identified low extreme precipitation quantiles in this specific period. Figure $8 \mathrm{~b}$ shows that the variability of the stations in the eastern part of Denmark to some degree is represented by the oscillation curve for Kbh, while Fig. 8c show that neither Fanoenor Vestervig represents the variation of the stations in Jutland. Annual box-plots of the $p f_{\mu}$ show no common regional patterns.

On the basis of the all 67 stations it is also investigated if the oscillating behaviour of $\lambda$ and $\mu$ is similar in some parts of the regions, as suggested by Table 1 . This is done by a Pearson correlation analysis (Helsel and Hirsch 2002; Willems 2013) where the correlation $\left(\rho_{\lambda \mu}\right)$ between $p f_{\lambda}$ and $p f_{\mu}$ is computed at each location, see Fig. 9. No regional patterns are found. A similar analysis on the unsmoothed $\lambda$ and $\mu$ series leads to the same conclusion.

\subsection{Seasonal variation and link to large-scale drivers}

A proxy of the EA index is calculated as the normalized difference between SLP in Gibraltar and the seven locations in Scandinavia where SLP series are available. Note 
Fig. 9 Regional variations of $\rho_{\lambda \mu} . \rho>0.5$ is marked with red, $0.2<\rho<0.5$ is marked with yellow, $-0.2<\rho<-0.2$ is marked with white,

$-0.2>\rho>0.5$ is marked with green and $\rho<-0.5$ is marked with blue

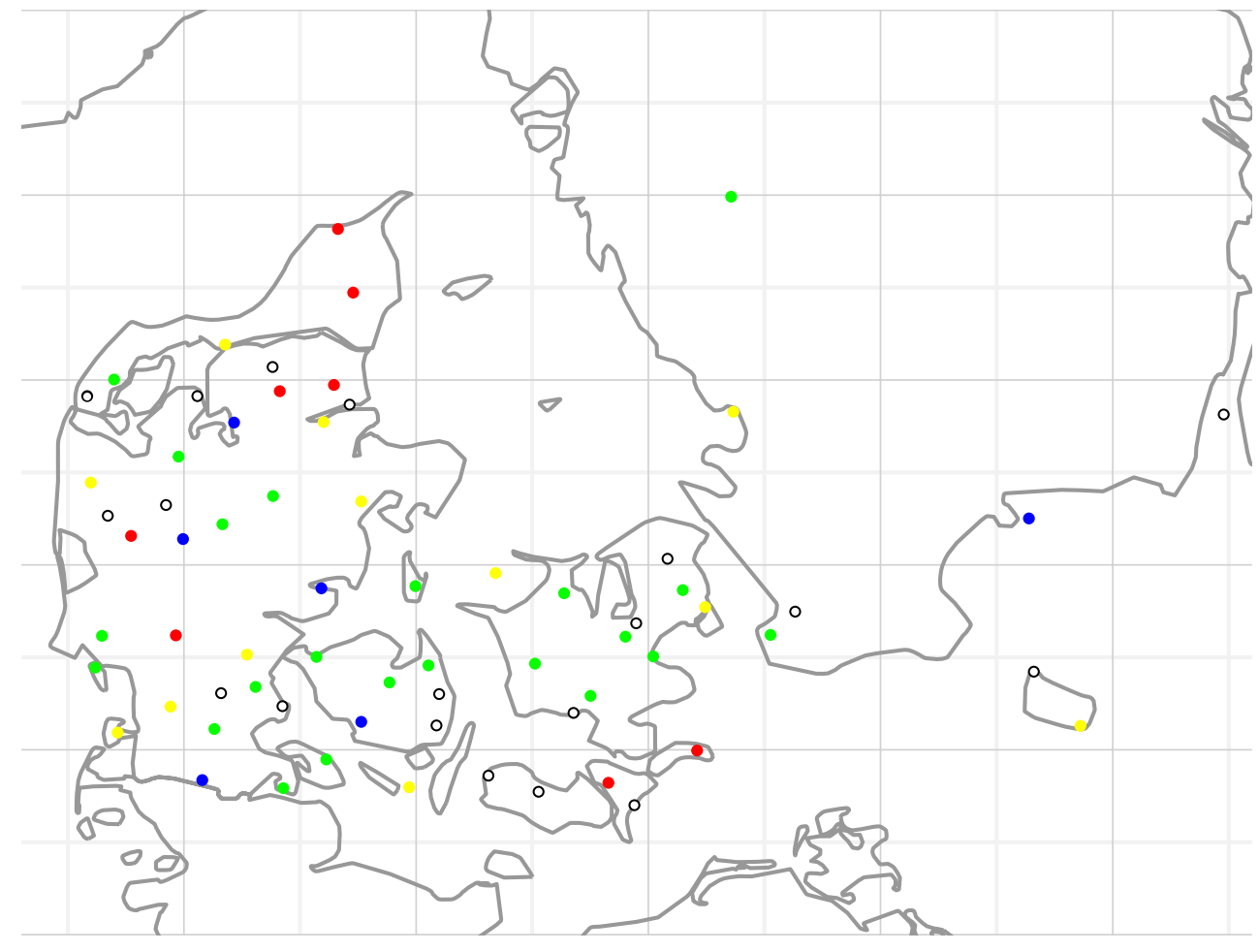

that the available SLP series do not include the most recent years. All series are smoothed by a 10 -year moving average. The multi-decadal variations of the smoothed SLPD series are found to be very alike, hence only the GibraltarHaparanda series is shown below. The SLPD show a clear oscillating behaviour, but the pattern changes with the season. Figure 10 compares the multi-decadal variation of the May-Oct average of the Gibraltar-Haparanda SLPD series, with the EA index from NOAA (2013b) and the NAO index from CRU (2013). The EA and NAO indices also represent May-Oct and both have been smoothed by a 10-year moving average. As expected, the constructed SLPD series do not reflect the variation of NAO. There are more similarities between EA and the SLPD series, the two diverge in the beginning of the observation period, but show similar patterns after 1975. Hence, the simple station-based SLPD index is only partly a proxy of the more well-defined EA index.

A correlation analysis between the SLPD series for different seasonal averages and the $p f_{\lambda}$ series for Vestervig, Fanoe and Kbh, respectively, shows that part of the oscillating behaviour of $p f_{\lambda}$ can be explained by SLPD over the North Atlantic. A correlation of 0.50 is found between $p f_{\lambda}$ for Kbh and the May-Oct average of the SLPD, see Fig. 11. This corresponds well with the fact that the majority of the extreme events in Kbh occur in May-Oct. Also note that a phase shift of 2 years increases the correlation to 0.59 . The lack of data for the very recent years makes it unclear if the last oscillation peak that, as discussed in

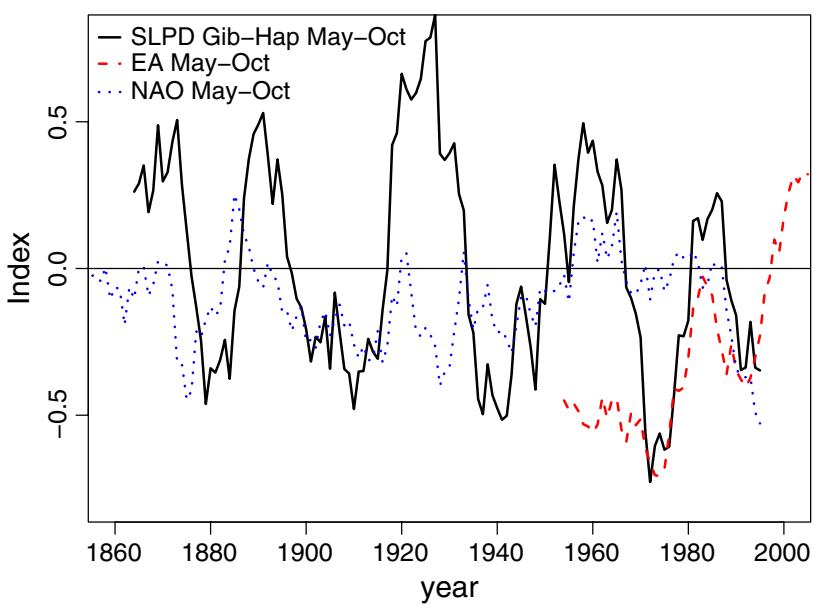

Fig. 10 Comparison of the SLPD index for Gibraltar-Haparanda, the EA index and the NAO index, all computed as annual averages over the period May-Oct and smoothed by a 10-year moving average

Sect. 4.1, appears larger and more persistent also is correlated to the SLPD over the North Atlantic. The continuous increase of the EA index indicates so. For the two western stations the extreme events occur in Jun-Dec, however SLPD averages of the same period do not explain the variations of neither Fanoe nor Vestervig. Seasonal PDS are estimated extracting only extremes in May-Oct for Kbh, and Jun-Dec for Fanoe and Vestervig. For both Kbh and Fanoe this increases the correlation with SLPD averaged over the same months. Additional seasonal analyses show that the 


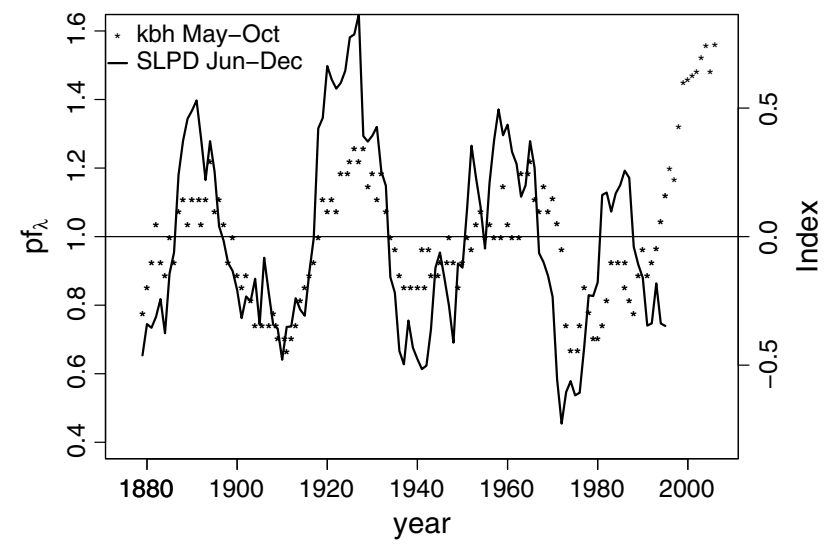

Fig. 11 SLPD index for Gibraltar-Haparanda in the period May-Oct (secondary axis) plotted together with $\mathrm{pf}_{\lambda}$ for $\mathrm{Kbh}$ (primary axis)

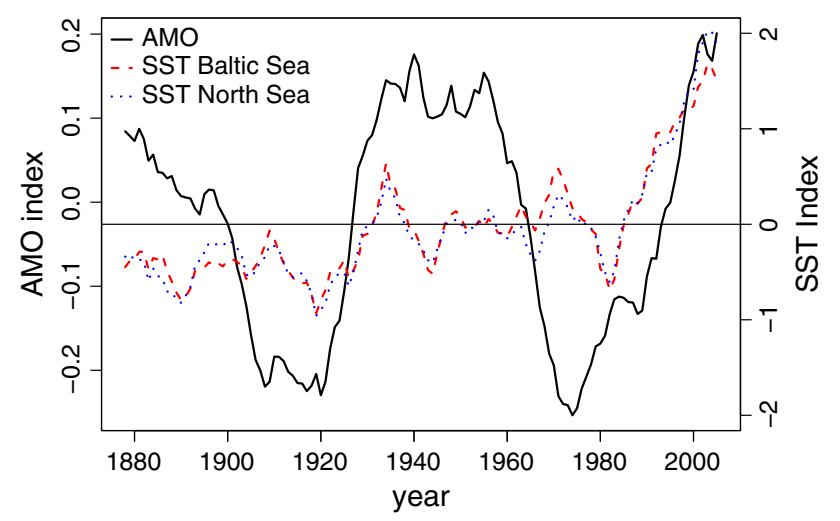

Fig. 12 Comparison of the annual AMO index (primary axis) and the normalized annual SST of the North Sea (along the coast of Jutland) and the Baltic Sea (between Zealand and Bornholm). All series are smoothed by a 10 -year moving average

general increase in $p f_{\lambda}$ is driven by events occurring in the winter season even though a substantial part of the extreme events occur during the summer period.

The AMO has a cycle of $65-80$ years (Enfield et al. 2001) that is easy to identify in the smoothed index shown in Fig. 12. The smoothed normalized annual SST of the North Sea and the Baltic Sea also fluctuates but with a higher frequency and a less distinct cycle, see Fig. 12. The AMO index is calculated from a linearly detrended dataset of the North Atlantic SST going from Equator to the Arctic regions, and the dissimilarity with SST fluctuations of local Danish waters is hence not surprising. The SST for the North Sea and Baltic Sea, respectively, are however very alike and so is the annual and summer average. The AMO cycle is not correlated to the observed $p f_{\lambda}$ or the observed $p f_{\mu}$ pattern. There is a weak correlation between the SST variations and $p f_{\mu}$ for some stations, e.g. in the late 1930' ties where the SST peaks together with the $p f_{\mu}$ in Kbh and
Samsoe, see Fig. 4. Finally note that the SST increases dramatically in the last part of the observation period.

\section{Discussion and conclusion}

The multi-decadal variation of extreme rainfall in Denmark and the southern part of Sweden has been quantified. The frequency of the extreme events shows both a general increase from 1874 to present and a cyclic pattern with a period of 25-35 years. The magnitude of the extreme events also shows a cyclic pattern, but with a shorter period. For two out of the six stations with long records the magnitude of the extreme events also showed an increase over time. The conclusions are based on smoothed series where high frequency variability is removed at the expense of the introduction of autocorrelation.

There are well-known regional variations in the rainfall over Denmark, and the present analysis indicates that the long term variation of the rainfall extremes also depends on the region. This can be described by a phase shift in the cyclic pattern of the frequency of the extreme events over Denmark. However, three out of the six stations with long records are located on small islands, where the variations of the extreme precipitation might not represent typical large scale variations within the region. Hence, regional analysis was attempted on a dataset with a denser gauge network even though the relatively short observation period of these records most likely effects the estimation of the oscillation signal. The regional analysis found a countrywide low period in 1970-1979, and a generally more varied oscillation signal along the west coast of Denmark. This could indicate that the variation of extreme rainfall in this area is dominated by the passage of low pressure systems, and that the cyclic pattern at a given station, hence, is partly driven by variations in the dominating storm tracks. The oscillations diminish in the central part of Jutland, but reoccur in the eastern part of Denmark, where the cyclic pattern for Kbh might be representative for the entire area. Differences in the main season of occurrences of rainfall extremes between the West coast of Denmark and the rest of the country confirm this regionalization.

It is furthermore shown that an index derived from SLPD between Gibraltar (Spain) and Haparanda (Sweden) can explain $50 \%$ of the multi-decadal variations in the frequency of the extreme events for the long record station located in Kbh. This index partly resamples the EA pattern, which continues to increase throughout the observation period where SLP at Gibraltar are not available. The most recent oscillation high in the Kbh series appears larger and more persistent. Although the series is too short to allow formal statistical testing of a hypothesis of change it might be interpreted as a sign of anthropogenic climate change. 
Therefore, it is highly relevant to evaluate if similar cyclic SLP patterns can be found in state-of-art climate model simulations, if they drive the variation of extremes in both the past and in the future and if the character of the oscillations change over time. In the search for a link between the variation of extreme rainfall and other large scale variables it was also found that high SST of the Danish waters potentially can lead to high magnitudes of the extreme events in the central and eastern part of Denmark.

The identification of a cyclic pattern in the extreme rainfall in Denmark is of high relevance for our understanding of the past and present non-stationarities in flood hazard. It shows that short term detections of changes in heavy rainfall should be interpreted with great care. The found SLPD cycle might explain parts of the multi-decadal variation, but the importance of other large-scale drivers could increase as the climate changes.

The presented analysis is explorative and mainly based on smoothed series thus focussing on an identification of potential multi-decadal variation in extreme rainfall. The overall variability of extremes is high as shown by the spectral analysis of $\lambda$ and $\mu$. An analysis with the purpose of prediction should not focus on the multi-decadal variability alone but include all relevant oscillations in the full spectrum of frequencies. These can be explored e.g. by the method of empirical mode decomposition suggested by Lee and Ouarda (2010). Such a study in combination with a more thorough analysis of causal relationships between the observed extreme rainfall and large scale oscillations might enable projections of future behaviour of precipitation extremes. While the current study has focussed on and identified cyclical behaviour of extreme precipitation the developed models do not yield a sufficient understanding of the processes to allow such projections.

Acknowledgments This work was carried out with the support of the Danish Strategic Research Council as part of the project "Centre for Regional Change in the Earth System", contract no. 09-066868 and from The Foundation for Development of Technology in the Danish Water Sector, contract no. 7492-2012. The authors are also grateful to the Danish Meteorological Institute and Lars Bengtsson, Department of Water Resources Engineering, Lund University, Sweden for providing the data, and Patrick Willems, Hydraulics Division, Katholieke Universiteit Leuven, and Martin Drews, Department of Management Engineering, Technical University of Denmark, for valuable discussions.

\section{References}

Bengtsson L, Rana A (2013) Long-term change of daily and multi-daily precipitation in southern Sweden. Hydrol Process 28(6):2897-2911

Cappelen J. (2013) Denmark-DMI historical climate data collection 1768-2012. Technical report 13-02. Danish Meteorological Institute, Ministry of Climate and Energy. Copenhagen, Denmark
Coles S (2001) An introduction to statistical modeling of extreme values. Springer, London

CRU (2013) North Atlantic Oscillation, Climatic Research Unit, University of East Anglia, Norwich U.K., http://www.cru.uea.ac. uk/cru/data/nao/, Accessed October 2013

Dai A (2013) The influence of the inter-decadal Pacific oscillation on US precipitation during 1923-2010. Clim Dyn 41:633-646

Dingman SL (1994) Physical hydrology. Prentice Hall Upper Saddle River, New Jersey, USA

Enfield DB, Mestas-Nunez AM, Trimble PJ (2001) The Atlantic multidecadal oscillation and its relation to rainfall and river flows in the continental US. Geophys Res Lett 28:2077-2080

Fowler AM, Hennessy KJ (1995) Potential impacts of global warming on the frequency and magnitude of heavy precipitation. Nat Hazards 11:283-303

Frich P, Rosenørn S, Madsen H, Jensen JJ. (1997) Observed precipitation in Denmark, 1961-1990. Technical report 97-8. Danish Meteorological Institute, Ministry of Transport. Copenhagen, Denmark

Gregersen IB, Madsen H, Rosbjerg D, Arnbjerg-Nielsen K (2013a) A spatial and nonstationary model for the frequency of extreme rainfall events. Water Resour Res 49:127-136

Gregersen IB, Sørup HJD, Madsen H, Rosbjerg D, Mikkelsen PS, Arnbjerg-Nielsen K (2013b) Assessing future climatic changes of rainfall extremes at small spatio-temporal scales. Clim Change 118:783-797

Hadley Centre (2013) Hadley centre sea ice and sea surface temperature data set, Met Office Hadley Centre, Exeter U.K., http://www.metoffice.gov.uk/hadobs/hadisst/, Accessed October 2013

Heikkila U, Sorteberg A (2012) Characteristics of autumn-winter extreme precipitation on the Norwegian west coast identified by cluster analysis. Clim Dyn 39:929-939

Helsel DR, Hirsch RM (2002) Statistical methods in water resources. In: U.S. geological survey (ed) Techniques of water-resources investigations of the United States geological survey, Book 4, hydrologic analysis and interpretation. U.S. geological survey

Jones PD, Davies TD, Lister DH, Slonosky V, Jonsson T, Barring L, Jonsson P, Maheras P, Kolyva-Machera F, Barriendos M, MartinVide J, Rodriguez R, Alcoforado MJ, Wanner H, Pfister C, Luterbacher J, Rickli R, Schuepbach E, Kaas E, Schmith T, Jacobeit J, Beck C (1999) Monthly mean pressure reconstructions for Europe for the 1780-1995 period. Int J Climatol 19:347-364

Kysely J (2009) Trends in heavy precipitation in the Czech Republic over 1961-2005. Int J Climatol 29:1745-1758

Lee T, Ouarda T (2010) Long-term prediction of precipitation and hydrologic extremes with nonstationary oscillation processes. $\mathrm{J}$ Geophys Res 115:1-11

Lenderink G, Ev Meijgaard (2008) Increase in hourly precipitation extremes beyond expectations from temperature changes. Nat Geosci 1:511-514

Lundholm SC, Cappelen J (2010) Ekstremnedbør i Danmark 1961-2010-leverance til Koordineringsenhed for Forskning i klimaTilpasning (KFT). Technical report 10-17.Danish Meteorological Institute, Ministry of Climate and Energy. Copenhagen, Denmark

Lundholm SC, Cappelen J (2011) Extreme value analysis of 96 daily series of precipitation, Denmark 1961-2010. Technical report 11-08. Danish Meteorological Institute, Ministry of Climate and Energy. Copenhagen, Denmark

Lupikasza EB, Haensel S, Matschullat J (2011) Regional and seasonal variability of extreme precipitation trends in southern Poland and central-eastern Germany 1951-2006. Int J Climatol 31:2249-2271

Madsen H, Rasmussen PF, Rosbjerg D (1997) Comparison of annual maximum series and partial duration series methods for modeling 
extreme hydrologic events 1. At-site modeling. Water Resour Res 33:747-757

Madsen H, Mikkelsen PS, Rosbjerg D, Harremoes P (2002) Regional estimation of rainfall intensity-duration-frequency curves using generalized least squares regression of partial duration series statistics. Water Resour Res. doi:10.1029/2001WR001125

Min SK, Zhang X, Zwiers FW, Hegerl GC (2011) Human contribution to more-intense precipitation extremes. Nature 470:376-379

NOAA (2013a) Climate time series atlantic multidecadal oscillation index, Earth System Research Laboratory, Physical Sciences Division, National Oceanic and Atmospheric Administration, Mayland U.S., http://www.esrl.noaa.gov/psd/ data/timeseries/AMO/, Accessed September 2013

NOAA (2013b) Northern hemisphere teleconnection patterns, http://www.cpc.ncep.noaa.gov/data/teledoc/telecontents.shtm 1, National Weather Service, National Oceanic and Atmospheric Administration, Mayland U.S., accessed September 2013

Ntegeka V, Willems P (2008) Trends and multidecadal oscillations in rainfall extremes, based on a more than 100-year time series of 10 min rainfall intensities at Uccle. Water Resour Res, Belgium. doi:10.1029/2007WR006471

Rayner NA, Parker DE, Horton EB, Folland CK, Alexander LV, Rowell DP, Kent EC, Kaplan A (2003) Global analyses of sea surface temperature, sea ice, and night marine air temperature since the late nineteenth century. J Geophys Res. doi:10.1029/2 002JD002670

Rodda JC, Little MA, Rodda HJE, McSharry PE (2010) A comparative study of the magnitude, frequency and distribution of intense rainfall in the United Kingdom. Int J Climatol 30:1776-1783

Scaife AA, Folland CK, Alexander LV, Moberg A, Knight JR (2008) European climate extremes and the north Atlantic oscillation. J Clim 21:72-83

Shumway RH, Stoffer DS (2010) Time series analysis and its applications. Springer, Germany

R Core Team (2012) R: A language and environment for statistical computing. R Foundation for Statistical Computing, Vienna, Austria. ISBN 3-900051-07-0, http://www.R-project.org/

Trenberth KE, Dai A, Rasmussen RM, Parsons DB (2003) The changing character of precipitation. Bull Am Meteorol Soc 84(9):1205-1217

Westra S, Alexander LV, Alexander LV, Zwiers FW (2013) Global increasing trends in annual maximum daily precipitation. J Clim 26:3904-3918

Wickham H (2009) ggplot2: elegant graphics for data analysis. Springer, New York

Willems P (2013) Multidecadal oscillatory behaviour of rainfall extremes in Europe. Clim Change 120:931-944 